\title{
The Development of Online Learning in Israeli Higher Education
}

\author{
Erez Cohen ${ }^{1} \&$ Nitza Davidovitch ${ }^{2}$ \\ ${ }^{1}$ Department of Middle Eastern Studies - Political Science, Ariel University, Israel \\ ${ }^{2}$ Head of the Ariel University Center's Unit of Academic Assessment and Development \& Head of the \\ Israeli Consortium of Faculty Development Centers, Ariel University, Israel \\ Correspondence: Erez Cohen, Department of Middle Eastern Studies - Political Science, Ariel University, Israel. \\ E-mail: nmn115@ariel.ac.il
}

Received: June 10, 2020 Accepted: July 12, 2020 Online Published: July 15, 2020

doi:10.5539/jel.v9n5p15 URL: https://doi.org/10.5539/jel.v9n5p15

\begin{abstract}
The COVID-19 pandemic that swept through the world in 2020 and forced the various higher education institutions in Israel and around the world to promptly embrace the online teaching method, placed on the agenda the question of this method's efficacy as well as deliberations regarding its future implications. The current study reviews the development of online teaching in Israel's higher education and examines whether this development derives from an organized and well-formulated public policy with a view to the future or is the result of the constraints and various actors within the free market. In addition, the study presents a case study of an academic institution, examining the opinions of students with regard to the benefits and shortcomings of online teaching. The research findings indicate that the development of online teaching in Israel is the result of needs, constraints, and opportunities that emerged in the free market rather than a result of organized public policy by the Ministry of Education and the Council for Higher Education. Consequently, the study presents the various implications of these unregulated developments for the quality of teaching and for student satisfaction. The study illuminates a thorough discussion that should be conducted by movers of higher education and academic institutions concerning a new effective designation of the campuses following the COVID-19 crisis as well as the distinction between virtual and real-life dimensions of academic teaching.
\end{abstract}

Keywords: public policy, online learning, distance education, higher education

\section{Introduction}

The COVID-19 crisis that afflicted the world in general and Israel in particular as of the first quarter of 2020 has taken a heavy financial toll. These circumstances require both business and government authorities to change their regular manner of conduct and embrace more adaptive and efficient courses in the aim of maximally preserving their enduring activity. Such adaptive steps did not pass over the higher education system, which was compelled to rapidly find solutions for the challenging reality of a spreading pandemic that prevented continued physical activity in the various campuses. This system, which similar to the entire domestic educational system has been suffering for many years from intellectual stagnation and lacks the creative and dynamic action currently required, was compelled by the circumstances to formulate and develop innovative online teaching methods that will probably be preserved once the crisis dies down and routine is resumed.

The current study focuses on Israeli higher education as a case study, since this society is characterized by higher education rate (one of the highest in the world) on one hand, and by high level of innovation and advanced technology, on the other hand. This study has two intertwined aims: First, it seeks to explore the development of online teaching in Israel—is it a result of organized and predetermined public policy that seeks to adapt Israel's system of higher education to the currently available advanced teaching technologies, or is it a result of uncontrolled development embraced by the various institutions of higher education following demand and supply pressures (by students and faculty, respectively) in the higher education market, similar to decisions regarding determination of admission terms and the number of students in the various departments (Cohen \& Davidovitch, 2016). Then, the study explores and analyses how Israeli students experience and what they think about this teaching method that is encountered inadvertently, based on the findings of an attitude survey held at Ariel University, the case study for the current research. In addition, the study tries to link the findings of the attitude survey and the development of online teaching in Israel as found in the study. 


\subsection{Stages in Development of the Distance Learning Method}

The attempt to develop alternatives to the frontal teaching mode, which requires the teacher and the students to be present in a single physical space, is nothing new. In fact, it is possible to describe three generations of distance learning that evolved in the world of academic teaching and education even before the recent developments. The first generation was called "correspondence learning", describing a method that developed in the nineteenth century and was based on the ability to print study material and distribute it by post. This study method accumulated momentum and was used in elementary, secondary, academic, and vocational education, so much so that even $\mathrm{PhD}$ correspondence studies were offered. The second generation was called "distance learning", describing the expansion of teaching tools, complemented by broadcast media, video and audiotapes, and to a limited degree also computers (Note 1). The third generation was called "computer-mediated distance learning" and it utilized more recent means such as the internet, modular courses, computerized questionnaires, and so on (Sumner, 2000). In fact, the currently implemented online teaching technologies are considered the fourth or even fifth generation of distance learning.

Notably, despite the evolutionary development of learning patterns, the later generations of distance learning did not convert the early practices to others rather added new ones, and today as well relatively old-time models of distance learning are still utilized (Anderson \& Dron, 2011). Hence, at present there are in fact different models of online learning, from the familiar model of a teacher who gives a frontal lecture with no aids, thorough frontal lectures accompanied by a presentation, to innovative models that combine an array of content sources and are attempting to propose new, collaborative, and less centralist forms of learning. All these can be provided in a digital format available on the internet for viewing or for collaborative learning (Matt \& Fernandez, 2013).

\subsection{Massive Open Online Courses (MOOCs)}

Academic teaching through massive open online courses (MOOCs) began in 2008, but the turning point arrived three years later, when Stanford University in the United States launched three courses that attracted thousands of students from many countries around the world. A year later, in 2012, there was a big breakthrough in this field, when venture capital funds began to invest enormous sums in initiatives operated by MOOC providers (Note 2). Since then, this has become a central topic of academic and public discourse on higher education (McAuley, Stewart, Siemens, \& Cormier, 2010; Cho, 2012; Waldrop, 2013).

Therefore, many studies have examined the efficacy and various effects of this innovative teaching method (McKnight, 2006; Kim \& Bonk, 2006; Keohane, 2013; Deming, Goldin, Katz, \& Yuchtman, 2015). Of these, some explored the satisfaction of academic faculty members with the online teaching method (Bolliger \& Wasilik, 2009; Baran, Correia, \& Thompson, 2013). Others focused on barriers to online teaching and the roles of the faculty in this innovative learning environment (Shea, Pickett, \& Li, 2005; Keengwe \& Kidd, 2010) as well as the challenges it poses for them (Bennett \& Lockyer, 2004; Bourne \& Bacsich, 2009; Bonvillian \& Singer, 2013; Kebritchi, Lipschuetz, \& Santiague, 2017), while yet others focused on the satisfaction of students with the expansion of online teaching (Young, 2006) and their involvement in furthering the development of this trend (Robinson \& Hullinger, 2008).

In a growing number of cases, the contemporary employment world requires an academic degree as a prerequisite for employment and, indeed, an increasing part of the world's population has been acquiring an academic education in recent years (Bach, Haynes, \& Smith, 2007). At the same time, this era is characterized by considerable use of screens for viewing videoclips and photographs. These two trends are interrelated and make embracing the online teaching method a natural and obvious process. As a result, in a growing number of academic courses a transition has been made from face-to-face teaching to online teaching (Pitt, 2016). The process of transitioning from a traditional teaching method to this innovative method requires the academic institution in general and the faculty in particular to meticulously plan activities, tasks, and evaluation methods, and to formulate a supportive policy (Orr, Williams, \& Pennington, 2009; Wanhua, 2012).

\subsection{The Teaching Method as an Opportunity for International Collaborations}

The online teaching method is a global trend that has been apparent for many years in various parts of the world and in many disciplines. This is evident in many articles published on the subject, as listed below. Juan and colleagues review the application of this method in mathematics and statistics courses in European universities (Juan, Steegmann, Huertas, Jesus Martinez, \& Sminosa, 2011). Similarly, the article published by Bosco and Rodríguez-Gómez attests to use of online teaching in Europe in general and in Spain in particular (Bosco \& Rodríguez-Gómez, 2011). Use of online teaching in higher education is also common in the Americas (Wang \& Chen, 2003; Dumitrica, 2017), Asia (Donoghue, 2006; Kang \& Song, 2007), and Africa (Escher, Noukakis, \& Aebischer, 2014; Olunivi \& Nhamo, 2013; Apena, 2016). 
Hence, it appears that this is a global development that is capable on one hand of affecting and changing the features of the higher education system in each country individually and on the other of increasing the efficacy of interrelations between the various academic institutions around the world. These relations can be manifested in sharing online courses for students in different countries as well as in conducting online research that will facilitate knowledge sharing among researchers from different countries. This depends, of course, on the removal of regulatory barriers to integrating the international higher education market in the domestic market, particularly by creating mechanisms for academic recognition of online courses or online degrees.

Notably, the opportunity to expand academic collaborations between institutions of higher education around the world thanks to the expanded use of this advanced teaching tool depends on use of an international language (usually English). However, most universities and colleges in Israel offer teaching programs based on use of Hebrew, with is the first language of most Israeli citizens. Therefore, it seems that at present this positive global impact is less relevant for Israeli academia. At the same time, it is entirely possible that in the near future we will see the development of efficient automatic translation tools that will eliminate this limitation.

The uniqueness of the current study is manifested in the attempt to link the development of online teaching in a given country (in this case Israel) and the extent of its assimilation and acceptance among the student body in that country. The degree of success will be measured by an attitude survey that will examine the opinion of students concerning this method, including its benefits and shortcomings. The findings of this survey are particularly relevant in the current era, when the world was exposed to the COVID-19 pandemic compelling institutions of higher education around the world to rapidly and promptly embrace online teaching. The successful assimilation of this innovative teaching pattern in such a short period probably depends on its development in each given country before the outbreak of the pandemic.

\section{Methodology}

This study will combine qualitative research, in the form of a commentary paper focusing on analysis of public policy on a specific topic and includes a literature review and position papers, and quantitative research that presenting data from an attitude survey conducted among students at Ariel University. The findings of the qualitative research are based on information taken from Israel's Council for Higher Education (CHE), databases of various Israeli academic institutions, and websites that collect information on online teaching (such as Digital Israel, Note 3). The findings of the quantitative research are based on an attitude survey held among students at Ariel University in Israel, which constitutes a case study examining the impact of embracing the online teaching pattern in Israel's system of higher education on its perceived benefits and shortcomings as perceived by the students.

\section{Findings}

As stated, the research findings begin by examining milestones in the development of online teaching in Israel's system of higher education and then present data from an attitude survey held among the study body at Ariel University, which is a case study of the effects of online teaching on the satisfaction of students in Israel.

\subsection{Milestones in the Development of Online Teaching in Israel's System of Higher Education}

Reviewing the development stages of online teaching at Israel's institutions of higher education points to a gradual process that began in the 1970s and rapidly expanded in 2020 with the outbreak of the global COVID-19 pandemic, as detailed below.

\subsubsection{Establishment of the Open University}

The first stage of online learning in Israel began in 1971, when the proposal (Note 4) to establish an Open University in Israel in the distance learning format, similar to the British Open University, was first raised, and five years later the Open University began its actual activities. The structure of the degree earned by students at this university is based on accumulating courses (the equivalent of credits), where each course has a designated website that includes study and enrichment materials, technological aids, a forum for consulting with academic faculty and for discussions among the students, as well as information about telephone guidance times. In some of the courses guidance for online learning is provided - interactive online guidance sessions where students can participate in classes through chat rooms and microphones, where the online sessions are recorded and can be viewed at students' leisure.

\subsubsection{Establishment of the Inter-University Computation Center}

About a decade and a half after establishment of the Open University, the second stage in the computer-assisted process of Israel's system of higher education, began with the establishment of an Inter-University Computation 
Center (IUCC) in 1990. This center, founded by Israel's research universities, began to deal with the development of communication and computerization infrastructure, digital information services, and advanced learning technologies. In addition, the IUCC furthers collaboration in these areas among member institutions, and between research institutions and industry. It also provides advanced computer-assisted services in research and teaching for members of academic faculties, researchers, and students at Israel's various universities.

\subsubsection{Establishment of an Inter-University Center for E-Learning}

In the early 2000s (2001), an inter-university center for e-learning (IUCEL) was established in Israel. This is a subunit of the IUCC that acts to promote use of teaching and learning technologies among all institutions of higher education in Israel (universities and academic colleges). The IUCEL placed the issue of integrating technology in learning at centerstage and constitutes, among other things, an inter-university forum for joint promotion of this issue in academia, while taking into account pedagogic needs. Operating versus various national entities, the IUCEL also formed extensive work ties with international institutions and organizations acting to further the use of advanced teaching and learning technologies. The IUCEL's extensive activity in areas of technology, pedagogy, innovations, accessibility, legal aspects and copyrights, support and guidance, research, and others, facilitated the significant advancement of learning technologies within Israel's various institutions of higher education.

\subsubsection{Establishment of the "Digital Israel" National Initiative by the Ministry for Social Equality}

The next stage in the development of online teaching in higher education was the by-product of an extensive national process unrelated directly to the system of higher education. This is the process of establishing a national initiative called "Digital Israel", implemented by the Ministry for Social Equality. Establishment of the initiative in 2015 expressed the national policy of using media and information technologies, formulated several years earlier, where several main core domains were defined that require policy adaptations to the digital era.

This national initiative aims to promote the growth of digital industries in Israel, support the shaping of an innovative environment, improve and assimilate the digital revolution in the work of the government and of the public sphere, as well as encourage and help citizens and businesses utilize the benefits of media and information technologies and data driven information. The premise of this program is that Israel must powerfully and rapidly advance to the front of the digital era in order to ensure its continued economic flourishing and the well-being of its citizens, while attending to all its population groups and sectors, as part of an overall conception of promoting social cohesiveness and diversity, empowering individuals, and reducing social, geographical, and economic disparities. Hence, in practice the "digital revolution" is capable of assisting in bringing the peripheral regions closer to the center and in increasing access to social and public products from afar in a way that will facilitate equal and easily available provision of services to distant populations.

In fact, the ministry that initiated the "Digital Israel" enterprise was the Ministry of Social Equality, which took action to advance processes of digitation in the various health, welfare, and social services fields, in order to reduce disparities and generate social equality in Israel. The social services defined in this initiative included the educational domain, in the aim of furthering increased access to education and higher education for disadvantaged population groups within Israeli society. These groups are defined as economically challenged, lacking the means to become integrated in the system of higher education, as well as groups that live at a geographical distance from institutions of higher education, which is a barrier to integration. By means of distance learning it is possible to form new opportunities for students living in the geographical periphery to become familiar with the array of courses given by top teachers who live in areas that are distant from them.

\subsubsection{Establishment of a Digital Learning Project - the IL Campus}

The development of information and media technologies in education and higher education, expedited thanks to the "Digital Israel" initiative, was embraced gratefully by Israel's Council for Higher Education (CHE) and its Planning and Budgeting Committee (PBC). The CHE and the PBC, together with the "Digital Israel" national initiative at the Ministry of Social Equality, began operating to further digital learning as a tool for improving the quality of teaching and the learning experience, increase access to higher education for all parts of the population in Israel, and enhance the status of Israeli academia around the world. Among other things, efforts have been made since 2016 to promote and expand use of digital academic courses in Israel by means of a series of calls for proposals distributed among institutions of higher education. These calls for proposals served as the basis for providing support to funded institutions for producing and/or converting digital academic courses and uploading them to the various platforms. These projects of the CHE, the PBC, and the Ministry of Social Equality, were included within a wide program designated "digital learning"- the IL campus. Indeed, once the CHE joined forces with the national project of the Ministry of Social Equality, Israel's various institutions of higher 
education felt confident to develop and implement online teaching programs (Note 5) parallel to traditional teaching on the campuses. However, these programs were relatively small in scope and did not lead to a true revolution in academic teaching and in how higher education is consumed in Israel.

\subsubsection{Full Transition to Online Learning as a Real-Life Constraint During the COVID-19 Pandemic}

As a consequence of the COVID-19 pandemic that spread around the world in general and Israel in particular in early 2020, and the lockdown implemented as a result, campuses were closed and universities and colleges throughout the world were compelled to switch to emergency remote teaching. Although most of the teachers had no previous experience with online teaching, the urgent need to embrace a readily available and speedy technological solution compelled the CHE to issue new instructions whereby frontal teaching would no longer be possible at institutions of higher education (until routine life is resumed) and therefore during lockdown learning would be strictly online. This instruction urged Israel's academic institutions to further rapid guidance processes (both for the faculty and for the students), such that in a very short period almost all academic courses were provided online. This transition was made in a matter of days, with no time for planning, such that both the faculty and the students were compelled to embrace new teaching and learning methods and technologies at top speed, utilizing learning management systems, course websites, and digital tools for distance learning.

\subsection{The Impact of Online Teaching on the Satisfaction of Students in Israel}

The rapid and unregulated development of online teaching in Israel, as portrayed above, had various impacts on the quality of learning and on students' satisfaction with it. A survey held by Tel Aviv University among students (Note 6), examining their attitude to the efficacy of online teaching, presented initial findings regarding factors that facilitate distance teaching and learning, side by side with difficulties and barriers, as perceived by students (Cohen, Barot, Hagit, \& Ezra, 2020). The survey findings showed that, in students' opinion, online learning facilitates the flexibility to manage their time according to personal needs, lets them perform other daily tasks while learning, as well as to maintain their routine. Moreover, they perceive online teaching as facilitating a flexible study pace, as it is possible to listen to recordings of the lectures whenever and wherever convenient for them. In addition, the students report that learning at home is an advantage for them because they do not have to come to the campus, sparing them significant amounts of money and time. Furthermore, the very transition to online teaching allowed the semester to continue and prevented its cancellation, which might have disrupted their studies in particular and their life course in general. Then again, the students identified limitations and difficulties deriving from the transition to the online teaching method. One claim was that this teaching method leads to a drop in the quality of teaching, resulting both from the fact that some faculty members lack experience with this teaching pattern and find it hard to adjust to it and from technical faults and challenges that overshadow the continuity of the lectures. Students also reported a decline in motivation to study and a difficulty to maintain concentration when viewing an online lecture.

Another survey, held by the National Union of Israeli Students (Note 7), examined students' concerns and expectations towards the exams to be taken at the end of the online semester. The survey data indicated that nearly $60 \%$ of the respondents claimed that for the purpose of grading the course it would be preferable to replace the test with an alternative means of evaluation (such as a home assignment or final paper). The reasons for this contention are related to an array of student concerns with regard to online tests and include the concern that the material to be included in the online test will not match the material provided in online lectures, the significant concern that the home will not provide an adequate environment for administering a test (disturbances by children, siblings, neighbors, street noise, etc.), and the concern that the online test will allow cheating and thus may be unfair ("cheaters will be rewarded").

As stated, the current study presents a case study conducted by means of a wide survey among students at Ariel University with the aim of examining the opinion and attitudes of the student body at this academic institution regarding online teaching. The research population encompassed 1,400 respondents $(\mathrm{N}=1,400)$, of whom $52.7 \%$ were men and $47.3 \%$ women. Ninety six percent were undergraduate students, $43.3 \%$ were not employed, $71.5 \%$ were single, and $27.6 \%$ married. Socioeconomically, $7.9 \%$ were on a high level, $67.7 \%$ on a medium level, and $24.4 \%$ on a low level. Nonetheless, almost all $(90.3 \%)$ noted that they have the resources and tools necessary for online learning.

The survey questionnaire presented to respondents several claims related to the impact of online learning on the quality of learning, identifying its benefits and shortcomings. The respondents were asked to rank their response on a scale of 1 to 5 (where 1 is not at all and 5 is very much). Figure 1 below describes the number of respondents and the relative proportion of those who responded "very much" ( 5 on the scale) and "very little" (1 on the scale) to several statements related to the different effects of online learning on the quality of teaching and 
learning (Note 8).

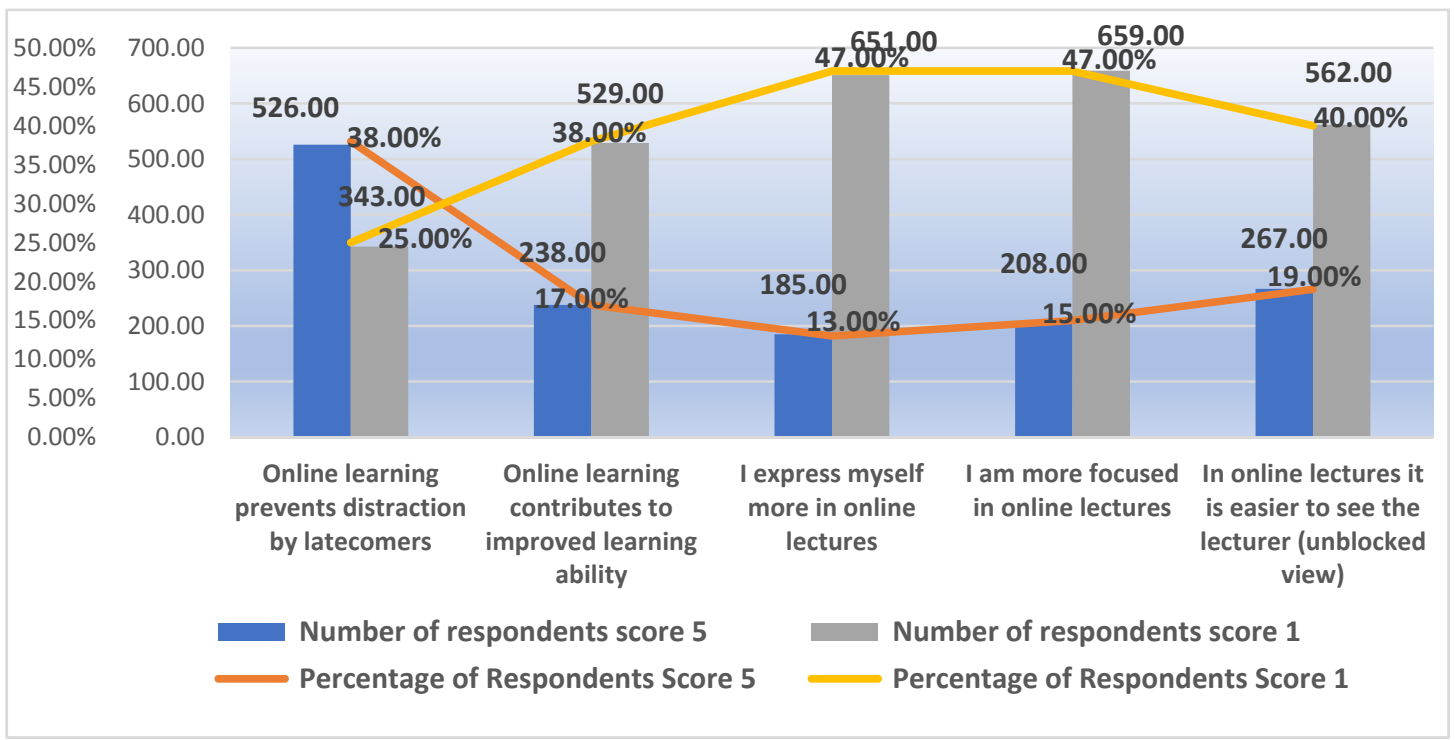

Figure 1. Contentions regarding improving learning abilities through online learning

The findings show that a very small proportion of those asked marked 5 (very much) for the question: "Does the online teaching method improve the learning ability?" $(17 \%$; 238). Similarly, only few gave this score to the contention that "This method allows students to better express themselves during lectures" $(13 \%$; 185$)$, the statement that online teaching allows them to maintain concentration during lectures $(15 \% ; 208)$, and the statement that in this method it is easier to see the lecturer $(19 \% ; 267)$. Then again, relatively more students reported that the online method prevents disturbances and distractions by participants in the lecture to a large degree $(38 \% ; 526)$.

Figure 2 below presents the benefits ascribed to online teaching as identified by the survey participants.

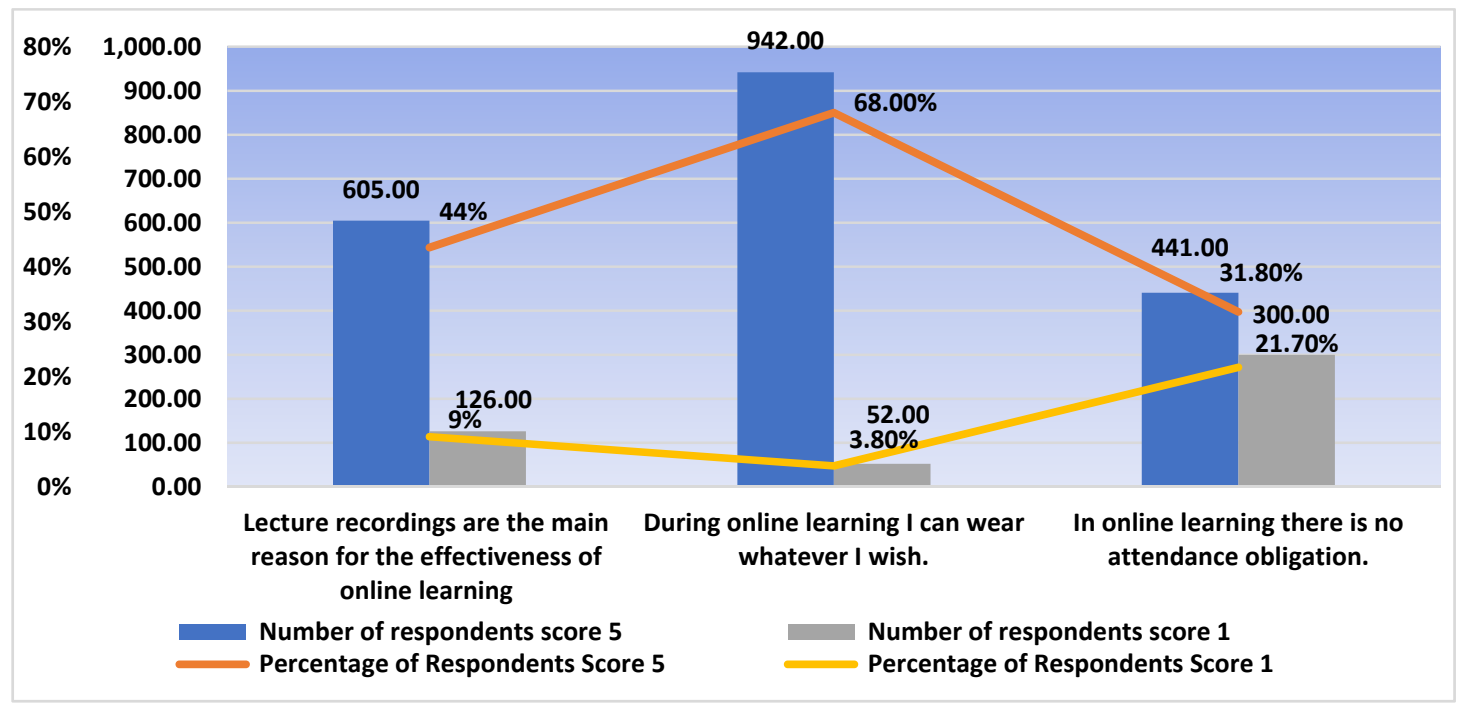

Figure 2. Contentions regarding the benefits of online learning for the students

It is evident from the survey findings that the students identify three prominent benefits of the online teaching method. The most conspicuous benefit, scored 5 by many students, is related to the convenience of this method in allowing students to wear whatever they wish to online lectures $(68 \%$; 942). The second benefit, scored 5 by 
the students, has to do with the possibility of recording lectures, which according to the respondents is the main reason for the effectiveness of this teaching method $(44 \% ; 605)$. Another benefit of the online teaching pattern, scored 5 by many students, concerns the fact that there is no attendance obligation for this type of lectures ( $32 \%$; 441).

Beside the benefits presented above, the students also identified several shortcomings related to the online teaching method. Figure 3 below presents the main ones.

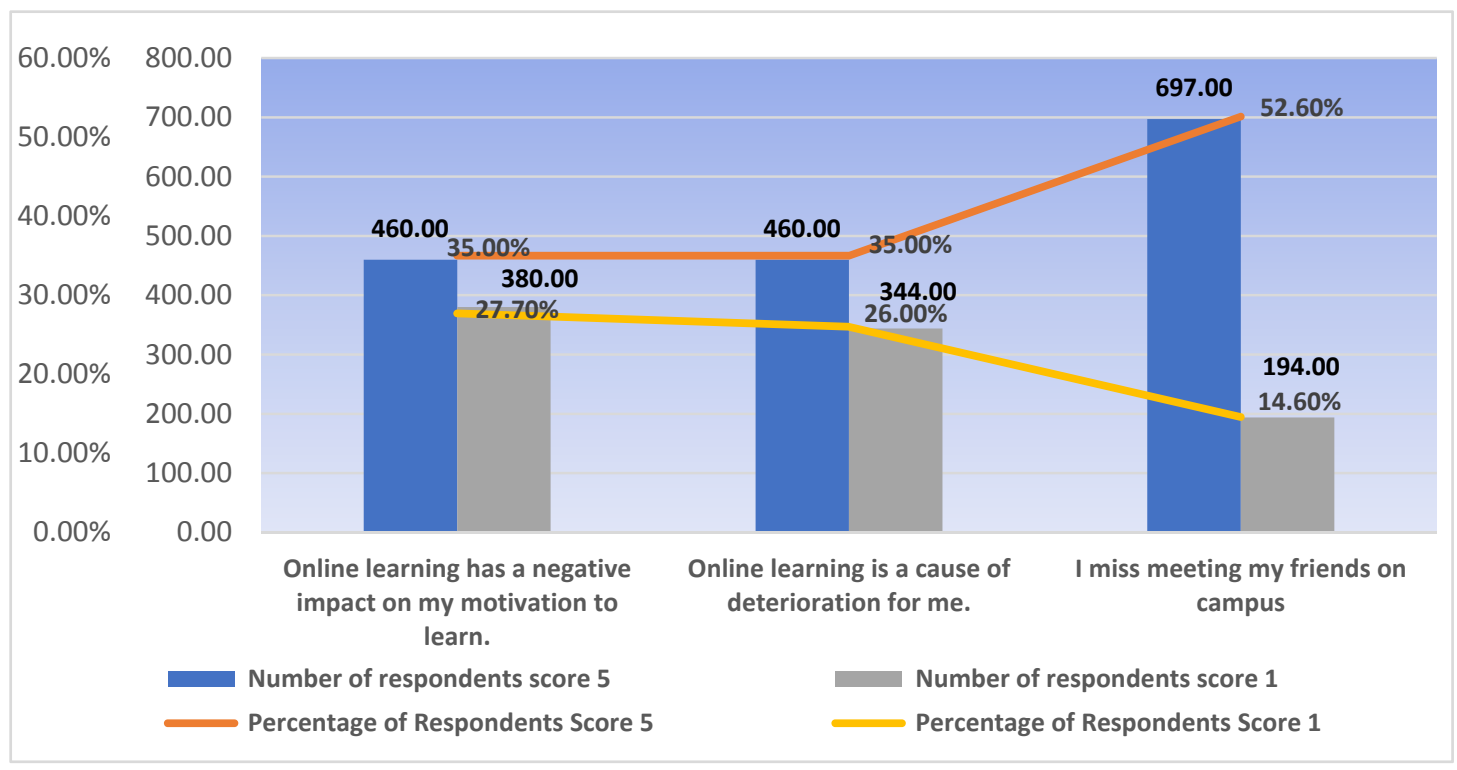

Figure 3. Contentions regarding the shortcomings of online learning for the students.

The findings in the figure above show that the most significant shortcoming ascribed to the online teaching method is students' inability to see their friends on campus $(52.6 \%$; 697). In addition, the students claimed that this teaching method reduces their motivation and leads to a decline in their studies $(27 \% ; 460)$.

The findings of this survey seem to be compatible with those of previous surveys conducted at Tel Aviv University and on behalf of the National Union of Israeli Students. All three surveys show that it is evident that side by side with the prominent benefits of the online teaching method as perceived by the students, this teaching pattern also has considerable disadvantages and limitations.

\section{Discussion}

The review of online teaching in Israel and its evolvement indicates a development deriving from needs and opportunities formed within a higher education market free of government regulatory steps and direction. This development began with the need of diverse higher education clients whose life style, demographic features, and other limitations and constraints did not allow them to become integrated in higher studies that require physical attendance of an academic institution in order to acquire a degree. Therefore, in the aim of meeting this need, the Open University was established in Israel in the mid-1970s, facilitating online interactive guidance and teaching sessions that can be viewed when and where convenient for these clients.

The origins of the second stage in the development of online teaching in Israel's system of higher education establishment of the Inter-University Computation Center (IUCC) in 1990-was the need raised by Israeli research universities, which sought to further collaborations in the fields of teaching and research. The establishment of this center helped improve technologies that facilitate online interaction among the universities themselves and between them and the students. The next stage of development continued the previous stage, with the establishment of an inter-university center for e-learning (IUCEL) in the early 2000s (2001), which expanded the integration of remote teaching technologies to academic colleges operating in Israel at the time, while improving these technologies.

The next stage in the development of online teaching in Israel in 2015 was indeed related to a government ministry and to the purposeful policy of those heading it, but it was not the Ministry of Education or the Council 
for Higher Education (CHE) that instituted policy for furthering this topic. In fact, the fourth stage of development is a result of lengthy national policy furthering use of information and media technologies and adapting public administration to the digital era. This policy was first implemented by the Ministry of Social Equality that operated to promote digitization processes in various areas as part of a project called "Digital Israel", with the purpose of advancing social cohesiveness, empowering individuals, and reducing Israel's social, geographical, and economic disparities. In these processes, the ministry acted to expand use of online teaching methods with the purpose of increasing access to higher education from distant areas, and these contributed to expanding this teaching pattern in Israel's system of higher education.

Therefore, it seems that in that year the leaders of the Ministry of Education in general and the higher education system in particular were merely passive actors in the emergence of this developmental stage. In fact, only a year after the "Digital Israel" initiative was established did the leaders of the CHE identify the opportunity presented by expansion of the Ministry of Social Equality's "Digital Israel" initiative to develop the system of higher education. Therefore, they decided to initiate an active policy of expanding use of online courses in Israel's various institutions of higher education (a fourth stage in the development of the process). This policy was manifested in the publication of a series of "calls for proposals" among institutions of higher education, promising them funding to produce and operate digital academic courses if they would choose to advance such activities.

Moreover, also the fifth and last stage of development of online teaching in Israel's higher education system derived from an external exigency not directly related to the higher education system per se. The spread of the COVID-19 pandemic in early 2020 mandated the implementation of policy steps limiting the movement of citizens in the public expanse and preventing people from congregating. Israeli policy enforced a type of lockdown on the local population in order to prevent further spread of the virus. Therefore, these circumstances did not allow continued frontal teaching in educational institutions in general and in institutions of higher education in particular and obliged the Ministry of Education to order a prompt and full transition to the online teaching method.

\section{Conclusions}

Hence, it appears that the development of online teaching in Israel is a result of needs, constraints, and opportunities arising from the free market related to higher education rather than the outcome of an organized public policy by the Ministry of Education and the CHE. In fact, the emergence of the various stages of development as presented in this article is related to students' needs (henceforth: customers/consumers) (Note 9), opportunities for obtaining economic and financial benefits by institutions of higher education (henceforth: producers/providers) (Note 10), and limitations and constraints on overall activities in the education market (Note 11). This conclusion regarding the lack of advance planning by Israel's system of higher education, the passivity, conservatism, and lack of innovation that characterize it, as well as its inclination to preserve the current stage without taking into account the changing circumstances and the challenges posed by the future, is nothing new and was evident in previous studies that examined its various features (Cohen \& Davidovitch, 2015; Cohen, 2018). Moreover, the study by Almog and Almog, that examined the online teaching revolution within Israel's system of higher education asserts that not only was this revolution enforced on the institutions of higher education from without, rather those institutions purposefully delayed its emergence for various considerations until giving in to present needs and to the constraints of circumstances shaped during the COVID-19 pandemic crisis (Almog \& Almog, 2020).

This assertion regarding a conservative policy that is delaying technological developments is surprising due to the fact that Israel is at the front of global technological knowledge and is characterized by world-leading technological innovativeness. Data provided by the "Digital Israel" initiative (Note 12) indicates that Israel, know as the "start-up nation", occupies the second place in the world for investments in research and development as a proportion of its GDP (Note 13), its capital risk investments are among the highest in the world (Note 14), and it is ranked high on the international competitiveness index of the Global Economic Forum for indicators of innovativeness and technological readiness. In addition, Israeli consumers are perceived as "early adopters" of innovative technologies and services, such that the country has a high standard foundation for assimilating digital services. The high rate (Note 15) of smartphone assimilation in Israel, constituting a significant facilitator of adopting digital applications, is also notable.

Then again, despite Israeli innovativeness and the advanced technologies utilized by the domestic hi-tech industry, the potential and benefits inherent in the digital era have not yet significantly trickled into all sectors of the economy and of the population (Note 16). In Israel there is a significant digital divide (Note 17) between 
different population groups, some of whom use and utilize the potential inherent in technology and in the digital era while others (particularly disadvantaged population groups) do not take part in this process and do not benefit from the products of technology and digitization.

As stated, the purpose of establishing the "Digital Israel" national initiative in 2015 was, among other things, to act to reduce disparities in society by providing high standard education through remote teaching technologies. Despite this insight, the research findings indicate, as stated, a trend of procrastination by the Council for Higher Education in general and by the various academic institutions in particular with regard to embracing distance learning.

Moreover, the research findings also examined the implications of rapid and unregulated adoption of online teaching on Israeli students' satisfaction in academic institutions and indicated that despite the many benefits identified, they still perceive this method as having considerable limitations and shortcomings. Some of these limitations and shortcomings stem from the fact that the development of online teaching in Israel was shaped by free market forces and did not stem from a planning and regulating policy initiated by official authorities or other central organs in Israel's system of higher education. These circumstances might lead to many faults and limitations both within the system of higher education, such as harm to the quality of the faculty and to the level of teaching, and outside it, such as the employment market and the level of services provided in the domestic market (Cohen \& Davidovitch, 2015). It makes sense that if this development had not been shaped and planned by policy designers under free market forces, it would have been possible to preempt most of the limitations and difficulties that appear in the student surveys while also preventing the formation of other problems in the foreseeable future (Note 18).

In summary, there is a relationship between how online teaching evolved in Israel and how it is perceived by the students. Implementing online teaching based on free market forces and its constraints, with no regulatory direction, supervision, guidance, and training (for both students and faculty) by the heads of the higher education system, reveals problems, limitations, and difficulties that could have been avoided and that might lead in the future to real harm to the quality of teaching, the quality of learning, and the level of academic training. Hence, the study illuminates an extensive discussion that must take place among leaders of higher education and of academic institutions regarding a new and effective designation of the campuses upon conclusion of the COVID-19 pandemic and a distinction between virtual and real-life dimensions in academic teaching.

\section{References}

Almog, T., \& Almog, O. (2020). All the lies of the academy. Rishon Letzion: Yedioth Ahronoth Books. (Hebrew)

Anderson, T., \& Dron, J. (2011). Three generations of distance education pedagogy. The International Review of Research in Open and Distributed Learning, 12(3), 80-97. https://doi.org/10.19173/irrodl.v12i3.890

Bach, S., Haynes, P., \& Smith, J. L. (2006). Online learning and teaching in higher education. UK: McGraw-Hill Education.

Baran, E., Correia, A. P., \& Thompson, A. (2013). Tracing successful online teaching in higher education: Voices of exemplary online teachers. Teachers College Record, 115(3), 1-41.

Bennett, S., \& Lockyer, L. (2004). Becoming an online teacher: Adapting to a changed environment for teaching and learning in higher education. Educational Media International, 41(3), 231-248. https://doi.org/10.1080/09523980410001680842

Bolliger, D. U., \& Wasilik, O. (2009). Factors influencing faculty satisfaction with online teaching and learning in higher education. Distance Education, 30(1), 103-116. https://doi.org/10.1080/01587910902845949

Bonvillian, W. B., \& Singer, S. R. (2013). The online challenge to higher education. Issues in Science and Technology, 29(4), 23-30.

Bosco, A., \& Rodríguez - Gómez, D. (2011). Virtual university teaching: Contributions to innovation in higher education. The case of Online Geography at the Universitat Autònoma de Barcelona. Innovations in Education and Teaching International, 48(1), 13-23. https://doi.org/10.1080/14703297.2010.543772

Cho, M. H. (2012). Online student orientation in higher education: A developmental study. Educational Technology Research and Development, 60(6), 1051-1069. https://doi.org/10.1007/s11423-012-9271-4

Cohen, A., Barot, O., Hagit, G., \& Ezra, O. (2020). Student perceptions of online teaching in higher education in light of the Corona crisis: Promoting and inhibiting factors. School of Education, Tel Aviv University. (Hebrew) 
Cohen, E. (2018). Public policy for regulating the interaction between labor market supply and higher education demand-Israel as a case study. International Journal of Higher Education, 7(6), 150-160. https://doi.org/10.5430/ijhe.v7n6p150

Cohen, E., \& Davidovitch, N. (2015). Higher education between government policy and free market forces: The case of Israel. Economics \& Sociology, 8(1), 258. https://doi.org/10.14254/2071-789X.2015/8-1/20

Cohen, E., \& Davidovitch, N. (2016). Regulation of academia in Israel: Legislation, policy, and market forces. Journal of Education and Learning, 5(4), 165-180. https://doi.org/10.5539/jel.v5n4p165

Deming, D. J., Goldin, C., Katz, L. F., \& Yuchtman, N. (2015). Can online learning bend the higher education cost curve? American Economic Review, 105(5), 496-501. https://doi.org/10.1257/aer.p20151024

Donoghue, S. L. (2006). Institutional potential for online learning: A Hong Kong case study. Journal of Educational Technology \& Society, 9(4), 78-94.

Dumitrica, D. (2017). Fixing higher education through technology: Canadian media coverage of massive open online courses. Learning, Media and Technology, 42(4), 454-467. https://doi.org/10.1080/17439884.2017.1278021

Escher, G., Noukakis, D., \& Aebischer, P. (2014). Boosting higher education in Africa through shared massive open online courses (MOOCs). Education, Learning, Training: Critical Issues for Development, 195. https://doi.org/10.1163/9789004281158_011

Juan, A. A., Steegmann, C., Huertas, A., Jesus Martinez, M., \& Simosa, J. (2011). Teaching mathematics online in the European Area of Higher Education: An instructor's point of view. International Journal of Mathematical Education in Science and Technology, 42(2), 141-153. https://doi.org/10.1080/0020739X.2010.526254

Kang, F., \& Song, G. (2007). e-Learning in higher education in China: An overview. E-Learning Initiatives in China: Pedagogy, Policy and Culture.

Kebritchi, M., Lipschuetz, A., \& Santiague, L. (2017). Issues and challenges for teaching successful online courses in higher education: A literature review. Journal of Educational Technology Systems, 46(1), 4-29. https://doi.org/10.1177/0047239516661713

Keengwe, J., \& Kidd, T. T. (2010). Towards best practices in online learning and teaching in higher education. MERLOT Journal of Online Learning and Teaching, 6(2), 533-541.

Keohane, N. O. (2013). Higher education in the twenty-first century: Innovation, adaptation, preservation. PS: Political Science \& Politics, 46(1), 102-105. https://doi.org/10.1017/S1049096512001734

Kim, K. J., \& Bonk, C. J. (2006). The future of online teaching and learning in higher education. Educause Quarterly, 29(4), 22-30.

Matt, S., \& Fernandez, L. (2013). Before MOOCs, 'colleges of the air'. Chronicle of Higher Education, 40(2), $102-120$.

Mayadas, A. F., Bourne, J., \& Bacsich, P. (2009). Online education today. Science, 323(5910), 85-89. https://doi.org/10.1126/science.1168874

McAuley, A., Stewart, B., Siemens, G., \& Cormier, D. (2010). The MOOC model for digital practice.

McKnight, S. (2006). Changing the mindset: From traditional on-campus and distance education to online teaching and learning. In eLearning and Digital Publishing (pp. 45-67). Dordrecht: Springer. https://doi.org/10.1007/1-4020-3651-5_4

Nhamo, G. (2013). Massive open online courses (MOOCs) and green economy transition: Feasibility assessment for African higher education. Journal of Higher Education in Africa/Revue de l'enseignement supérieur en Afrique, 11(1-2), 101-119.

Oluniyi, O., \& Apena, T. T. (2016). Adoption of e-learning among instructors in higher institutions in Nigeria: A case study of Obafemi Awolowo University, Ile-Ife, Nigeria. The International Journal of Management Science and Information Technology, 20, 53-73.

Orr, R., Williams, M. R., \& Pennington, K. (2009). Institutional efforts to support faculty in online teaching. Innovative Higher Education, 34(4), 257. https://doi.org/10.1007/s10755-009-9111-6

Pitt, P. (2016). Visual ethics in online teaching and learning in higher education. In Multidisciplinary Research Perspectives in Education (pp. 131-137). Rotterdam: SensePublishers. 
https://doi.org/10.1007/978-94-6300-615-6_16

Robinson, C. C., \& Hullinger, H. (2008). New benchmarks in higher education: Student engagement in online learning. Journal of Education for Business, 84(2), 101-109. https://doi.org/10.3200/JOEB.84.2.101-109

Shea, P., Pickett, A., \& Li, C. S. (2005). Increasing access to higher education: A study of the diffusion of online teaching among 913 college faculty. The International Review of Research in Open and Distributed Learning, 6(2). https://doi.org/10.19173/irrodl.v6i2.238

Sumner, J. (2000). Serving the system: A critical history of distance education. Open Learning: The Journal of Open, Distance and e-Learning, 15(3), 267-285. https://doi.org/10.1080/713688409

Waldrop, M. M. (2013). Online learning: Campus 2.0. Nature, 495(7440), 160. https://doi.org/10.1038/495160a

Wang, Y. M., \& Chen, D. T. (2003). Catching the wave: Online learning in higher education on Guam. Educational Technology, 43(3), 54-59.

Wanhua, Z. (2012). The study on college education method reform based on online teaching mode. In Software Engineering and Knowledge Engineering: Theory and Practice (pp. 1089-1097). Berlin, Heidelberg: Springer. https://doi.org/10.1007/978-3-642-03718-4_133

Young, S. (2006). Student views of effective online teaching in higher education. The American Journal of Distance Education, 20(2), 65-77. https://doi.org/10.1207/s15389286ajde2002_2

\section{Notes}

Note 1. The most common application of this model was the establishment of Open University institutions around the world and in Israel.

Note 2. Initiatives such as Coursera, EdX, Udacity.

Note 3. http://www.amisalant.com/?p=12368

Note 4. The proposal was raised by a committee from the Weizmann Institute, appointed by the Council for Higher Education (CHE).

Note 5. For instance, Tel Aviv University's innovative learning center, called TAU Online-https://tauonline.tau.ac.il/about

Note 6. One hundred and eighty-three students from Tel Aviv University responded to the survey.

Note 7 . The survey respondents included 16,896 students belonging to 39 different academic institutions and to a variety of faculties ( $93 \%$ of respondents were undergraduate students).

Note 8 . These statements were chosen based on a survey conducted by Meno Geva for the National Union of Israeli Students (Meno Geva, 2020).

Note 9 . The need to acquire an education by remote learning among those with place- and time-related limitations.

Note 10. The readiness of the various institutions of higher education to advance projects of online teaching in light of the CHE's calls for proposals and in return for grants and financial support for this purpose.

Note 11. The COVID-19 pandemic that paralyzed the system of higher education in its frontal format and required a full transition to online teaching.

Note 12. Source: http://digital-israel.mag.calltext.co.il/pages/16

Note 13 . A total of $4.1 \%$ of the GDP, second only to South Korea that invests $4.3 \%$ of its GDP.

Note 14. A total of $\$ 170$ per capita, versus only $\$ 75$ by the next in turn, the United States.

Note 15 . Over $75 \%$.

Note 16. For example, despite the wide spread of communications infrastructure in the country, Israel is ranked only 24th of OECD countries in utilization of fixed broadband and 25th in the world for average surfing speed.

Note 17. "Digital divide" means the differences between individuals, groups, households, organizations, and geographical areas, in their level of access to the digital environment (computers, software, and internet) and in their level of digital literacy (learning skills and proficiencies and working in a computerized environment). The digital divide leads to aggravation of socioeconomic inequality, as disadvantaged groups have less access to information and to the necessary tools for advancement and development of the digital era. 
Note 18. An example of a future problem is the likely assumption that the institutions of higher education will take advantage of the window of opportunity that required a rapid transition to online teaching and act to promote economic reorganization steps that include cutting the number of teaching hours at the cost of increasing the number of those registered to each course, while taking advantage of the online teaching method that enables this, also in routine times once the COVID-19 pandemic has run its course.

\section{Appendix A}

\section{The Survey Questionnaire}

Please mark 1 (strongly disagree) to 5 (strongly agree) at all on the following statements (please circle):

\begin{tabular}{|c|c|c|c|c|c|}
\hline & $\begin{array}{l}1 \text { strongly } \\
\text { disagree }\end{array}$ & 2 & 3 & 4 & $\begin{array}{l}5 \text { Strongly } \\
\text { Agree }\end{array}$ \\
\hline Online teaching prevents distraction by latecomers. & 1 & 2 & 3 & 4 & 5 \\
\hline Online teaching contributes to improved learning ability. & 1 & $z$ & 3 & 4 & 5 \\
\hline I express myself more in online lectures. & 1 & 2 & 3 & 4 & 5 \\
\hline I am more focused in online lectures. & 1 & $z$ & 3 & 4 & 5 \\
\hline In online lectures it is easier to see the lecturer (unblocked view). & 1 & 2 & 3 & 4 & 5 \\
\hline Lecture recordings are the main reason for the effectiveness of online teaching. & 1 & 2 & 3 & 4 & 5 \\
\hline During online teaching I can wear whatever I wish. & 1 & 2 & 3 & 4 & 5 \\
\hline In online teaching there is no attendance obligation. & 1 & 2 & 3 & 4 & 5 \\
\hline Online learning has a negative impact on my motivation to learn. & 1 & 2 & 3 & 4 & 5 \\
\hline Online learning is a cause of deterioration for me. & 1 & 2 & 3 & 4 & 5 \\
\hline I miss meeting my friends on campus. & 1 & 2 & 3 & 4 & 5 \\
\hline
\end{tabular}

\section{Copyrights}

Copyright for this article is retained by the author, with first publication rights granted to the journal.

This is an open-access article distributed under the terms and conditions of the Creative Commons Attribution license (http://creativecommons.org/licenses/by/4.0/). 